\title{
Research on Financial Budget Performance Audit Platform Construction By Information System
}

\author{
Fangjie Wei ${ }^{1, a}$ \\ ${ }^{1}$ Shanghai University, Shanghai, China \\ aweifangjie2008@163.com
}

Keywords: Financial budget, Performance audit, Platform construction

\begin{abstract}
To construct the financial budget performance audit platform by information system, this paper describes cloud computing, the limitations of the traditional audit model and use cloud computing to construct audit platform. Finally, three recommendations are put forward aiming to construct financial budget performance audit platform by information system.
\end{abstract}

\section{Introduction}

Audit has played an increasingly important role in our country, with the gradual development and improvement of audit, the audit completed by hand and stand-alone computer audit is no longer able to meet the needs of the audit work. With the popularity of network applications in various industries and departments, the development and utilization of cloud computing become unavailable factors. The application of computer technology under network environment in audit supervision work is undeniable trends ${ }^{[1]}$. Cloud computing is that the user needs to submit to the server, the server will operate and distribute computing on a large number of distributed computers, rather than the local computer or a remote server, and finally provide simple output result to the user.

Budget execution audit refers to the audit institutions through a certain way on the budget unit of oversight activities of economy, efficiency and effectiveness of budget execution. Through performance audits, evaluate the government to use public funds and strengthen public financial responsibility to find out the impact of public spending efficiency reasons, exposing waste and mismanagement loss, helping the audited entity to take effective measures to improve management and control system to improve efficiency ${ }^{[2]}$. With the annual growth of public spending, the public strongly demand the establishment of an efficient government, therefore, more and more attention are paid on the development of the National Audit Office performance audit of the budget execution in the audit process. The introduction of performance auditing expanded the scope of our audit of the implementation of the government budget. According to statistics, in 2003, there are 13 central departments conducting budget performance audit, while in 2010, it had increased to 53 departments. The corresponding number of audits secondary budget units had increased from 41 to $410^{[3,4]}$.

At this stage, with the continuous development of China's financial reform, the internal purchase and balance of payments adopted by the state, budget and treasury centralized payment of various departments have all taken appropriate reforms measures to continuously improve the flow path of fiscal funds. China's "Audit" and "supervision by the NPC Law" have had a greater impact on the audit of the budget, financial revenue and expenditure audit. But China's current government audit also confined to the implementation of the budget, the purpose of the audit is the error, suddenly neglecting the audit and assessment on performance of the government budget funds. Therefore, the traditional budget execution audit cannot make a scientific judgment accurately about the government's financial capital, which makes audit government funds audit realistic inevitability.

\section{Prospects of cloud computing}

In fact, the application of cloud computing is the cloud service, mainly reflected in the following aspects:

1. SAAS and platform service 
This type of cloud computing passes program into the hundreds of thousands of users through a browser. In the eyes of the user, it will save spending on servers and software licenses, they do not need to buy equipment or software prior authorization server. From a supplier point of view, it only needs to maintain a program with much lower cost.

2. Network service

Network services based on cloud computing is very broad, from a decentralized business service to a full range of API. Network service providers can offer API to allow developers to develop more Internet-based applications, rather than providing stand-alone program.

3. Business services platform and cloud computing integration

Business Services platform is hybrid applications of SAAS and MSP, such cloud computing provide a platform for the interaction between users and providers. Cloud computing integration is providing similar services on the Internet companies to integrate, so that users can more easily compare and choose their own service provider.

\section{The limitations of the traditional audit model}

In our traditional budget audit work, the budget funds are important re-audit budget point links, with no clear zone for financial management decisions, regulatory and accounting management. This leads to that a lot of government special funds within the department are diverted, misappropriated for no reason or other reasons for a loss, resulting in that our government problems on budget funds cannot be avoided effectively ${ }^{[5]}$. For this reason, the concept of innovation traditional auditing is a necessary requirement of the new era of budget implementation audit to continuously improve the scientific results of the audit and give full play to its reference value and improve the accuracy of project implementation and decision makers.

Traditional budget execution audit primarily aims to investigate for a variety of illegal activities and make legitimacy as the main criteria for judging the value ${ }^{[6]}$. In the actual audit work, the staff take this work as a mechanical task to complete, and make "the discovery process in violation of budget implementation law violations" for the task ${ }^{[7]}$, rather than to take promoting the effective development of government departments as a work.

Actively seeking to improve the performance audit of the audited organization or project, one of the successful performance audit standards is the ability to influence government resource allocation and decision-making, as a political act, performance audits can have political consequences. Many aspects in our country should use audit performance, such as satellite engineering ${ }^{[8]}$, car engineering and so on ${ }^{[9]}$.

Traditional audit procedures stressed the need to conduct audits when developing audit programs, once the project is included in the annual audit plans, audit procedures on the statutory audit. However, the project is not only conducted the audit investigation before performance audit, but also conducted the performance audit feasibility analysis. Feasibility analysis including performance evaluation standards, audit evidence, audit methods and analytical methods. The current audit of budget execution has not yet reached the performance audit requirements ${ }^{[10]}$. Performance audit does not perform the audit listed separately from the budget, auditing project way more for routine audit performed in accordance with the annual audit plan. Annual audit plans usually follow the program in previous years, the scope and content of the audit budget audit units usually changes without major changes. The average amount of the audited entity can be seen in Table 1.

Table 1 Average amount of the audited entity

\begin{tabular}{llll}
\hline $\begin{array}{l}\text { Average amount } \\
\text { [million yuan] }\end{array}$ & 2010 year & 2011 year & 2012 year \\
\cline { 2 - 4 } & 59034.053 & 49090.803 & 35103.528 \\
\hline
\end{tabular}

The data in Table 1 shows that China's audit authorities have made on the budget implementation audit department for three consecutive years, problems found by the audit have improved to a certain extent. Next, we will discuss about how to construct financial budget performance audit platform by information system using cloud computing. 


\section{Financial budget performance audit platform construction}

During the execution of the budget, the government is entrusted by the public. The government manage and use the public funds and report the usage to the public. Then, the government audit departments to implement fiscal budget execution performance audits and issue audit reports, and government supervision departments oversight the implementation of the audit department rectification and the situation after the audit units. In order to provide better service for the public, the government fulfill its public delegate responsibility. From five technology areas including the legal, audit process, audit assessment, audit and supervision to build a platform for government auditors to ensure that budget execution performance audit can be made more effectively.

Performance audit legal system includes performance audit law, performance audit regulation, performance audit guidelines, and performance audit guidelines. To accelerate suitably for China to carry out audits of government performance, it is imperative to strengthen the legal system, the development of government performance auditing standards in line with China's national conditions. In the guidelines to the Government Performance Audit Concept, audit objects, audit purposes, audit procedures, the basic form of the audit report should be defined clearly, conduct performance audits for the auditor to provide clear guidance to the performance audit criteria as a measure to discriminate audit quality. It is an important yardstick to definite audit responsibility and risk-averse clearly.

Audit process platform construction is the audit process redesign. Given the shortcomings of traditional audit process, from the audit plan, audit implementation and audit reports stages to design implementation performance audit of the budget process. Budget evaluation criteria includes regulations and standards, budgeting and planning standards, historical standards, industry standards and expert opinions. Indicators includes budget management effectiveness, economic indicators, efficiency indicators, the effect of the application of indicators and targets.

Performance audit should include forensic audit methodology and audit evaluation methods. After determining the method of audit evidence, to further determine the audit evaluation methods around the audit objectives and audit evaluation criteria, capital efficiency of audited unit, the use of funds and the results of the trial project to determine performance, etc. When constructing audit platform, we often take cloud computing into consideration for its important role in our society. Financial data, trade and industry data, insurance data, tax data, customs data and power data should be included in audit platform when using cloud computing, with this idea, the audit platform with cloud computing can be shown in Fig. 1.

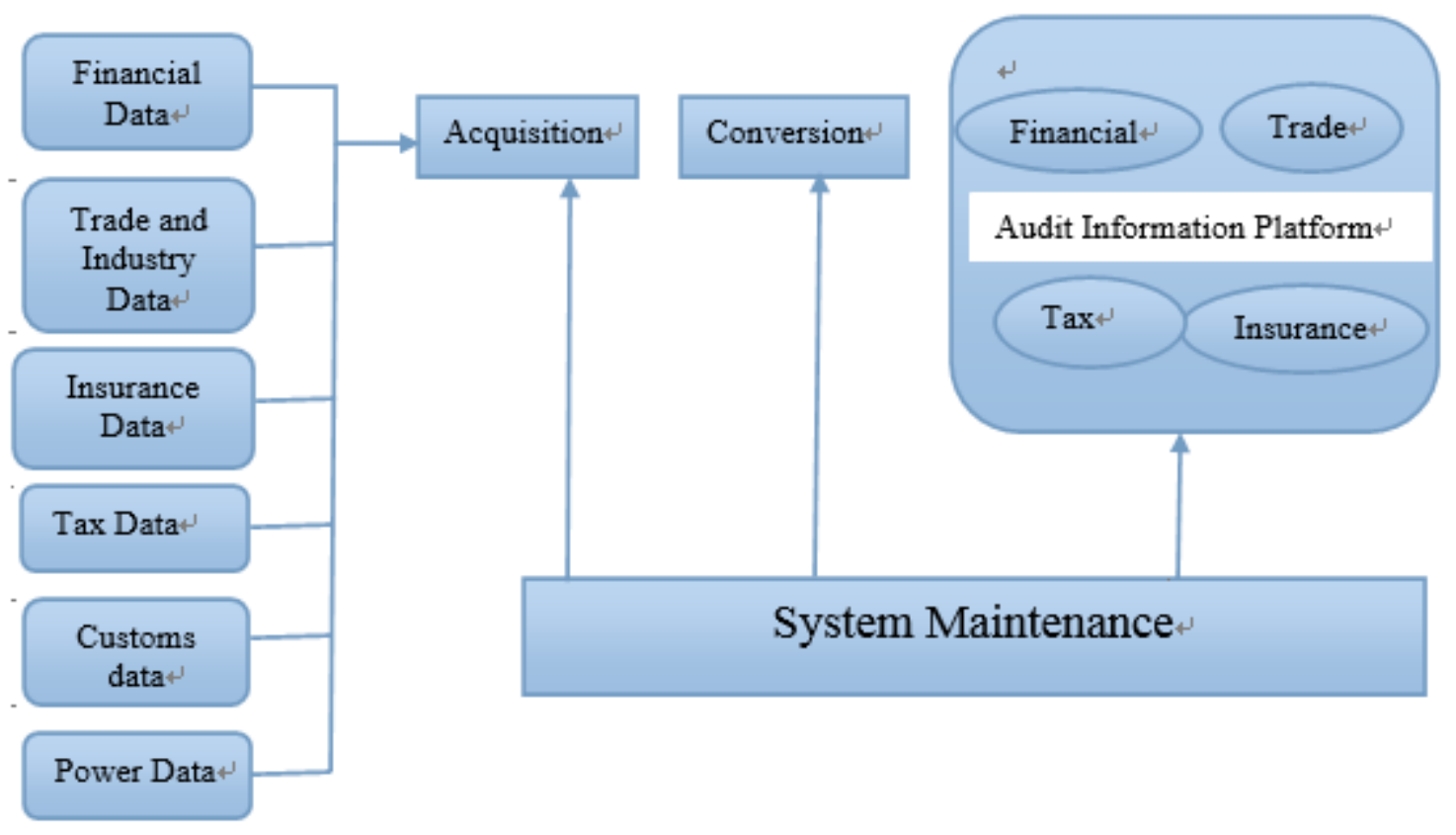

Fig. 1 Audit comprehensive information platform

In recent years, a strong proponent of improving audit results announcement system has been made in China. Budget implementation audit results announcement is published every year, but the 
audit findings have not been fully used, a lot of problems are not resolved. There are no effective audit recommendations implemented, so it did not meet the objectives of the audit. How to use the audit findings, the audit results should establish and improve the application on the basis of norms and strengthen supervision rectification, promoting improvements of violations of the audited entity and mismanagement issues. In terms of audit results application platform, performance audit institutions should summarize the problems during audit findings, find the common problems and causes. Integrate similar problems funding for audit results, analysis and refinement, from management decisions to meet the needs and put emphasis on decision-making and implementation of internal management systems to establish loopholes and find budget management and implementation of the management system of the existing problems, and propose a solution or suggestion from the management level. Complete audit announcement system to guarantee the implementation of the budget to use the results of the performance audit. Published results of the audit will not only make announcement of budget execution audit results, but also deal with the rectification of problems found by the audit and detailed announcement, so that the public are aware of and understand budget management and status of use and problems before and after rectification. In terms of supervision platform, some steps should also be conducted, such as establishing the follow-up inspection procedures, developing and implementing management responsibility, playing a role of social supervision and developing the cooperation mechanism in the implementation of audit oversight.

Performance audit is not something only belonging to a government audit agency, it also need the NPC, discipline, supervision, finance and other departments to closely cooperate in order to achieve better audit results. In addition, the performance audit also needs public participation, only put the interests of the people first, can we improve the performance audit platform construction to meet the conditions of our country, in order to better serve the people. Once the audit platform system building is completed, not only the efficiency of government departments will be greatly improved, but also it will save money and improve resource utilization to promote the establishment of other systems and lay the foundation for sustainable development of China's economy.

\section{Summary}

With the development of cloud computing and computer technology, audit platform construction will become more and more significant, some recommendations are put forward aiming to this.

First, by changing the traditional audit budget model, making it into a full range of auditing government fiscal funding model to continuously improve the effectiveness of the use of funds. In this way, computer technology should be used reasonably, many cloud services can offer platform construction a convenience and lower cost.

Second, it is to explore ways to audit financial performance and change the existing real legitimacy audit approach. Then, to make it become legally effective audit of government financial resources approach. In the course of budget implementation audit work carried out, audit staff not only should focus on budget funds use direction and budgeting, but also supervise and manage its actual funds use. From the original work with too much emphasis on the evaluation of fiscal and financial balance of authenticity to the attention of the financial accounts of the government's financial capital changes direction, and ultimately achieve financial budget money audits and real, effective unified legality audits to full performance audit of the budget funds. The purpose is to play a positive role in promoting the work of the government.

The third is to strengthen the comprehensive analysis to macroscopic effects instead of microscopic matter-audit. Continue to strengthen the comprehensive analysis capabilities, budget execution audit every year to prevent a similar phenomenon. First, the time of the audit inspection, the government should actively relate to the people's congresses and leadership of the annual fiscal budget implementation audit reporting. For example, for each year in the region's economic situation and financial revenue and expenditure for scientific and accurate audit assessments, and listen carefully comments and suggestions related to the leadership of the country and to help further define the relevant part of the focus of future work. In addition, to determine the "proposition papers." 
When conducting the audit summary, you should utilize a variety of analytical methods factor analysis method, the vertical and horizontal comparison method. Secondly, in the course of our audit work, we should pay attention to the actual situation to constantly adjust topics, do a good job "analysis articles", and continue to put forward countermeasures against new problems. Finally, good feedback and rectification work audit, the audit report for the previous year's proposed corrective measures to be further raised, and make tracking and feedback. And on the basis of comprehensive analysis, we should submit to the Government and the National People's Congress audit report, to truly reflect government budget funds questions found by the year's audit. Finally, put forward some audit recommendations to make a standardized management and improve the performance.

\section{References}

[1] De Renzio P. Aid, budgets and accountability: A survey article[J]. Development Policy Review, 2006, 24(6): 627-645.

[2]Liu C, Wang F, Shi K, et al. Robust $\mathrm{H} \infty$ Control for Satellite Attitude Control System with Uncertainties and Additive Perturbation[J]. International Journal of Science, 2014, 1(2):1-9.

[3]Ramkumar V, Krafchik W. The role of civil society organizations in auditing and public finance management[J]. 2006.

[4] Nixon B. Research and development performance measurement: a case study[J]. Management accounting research, 1998, 9(3): 329-355.

[5] Sung T J, You M. A method for establishing an online design audit platform[J]. Design Studies, 2007, 28(2): 195-211.

[6] Vijayalakshmi V. Fiscal Performance Audit: Public Record of Operations and Finance (PROOF) and Citizens’ Participation1[J]. Governance, 2004, 40(10): 1979-1999.

[7]Currie W. The IT strategy audit: formulation and performance measurement at a UK bank[J]. Managerial Auditing Journal, 1995, 10(1): 7-16.

[8] Liu C, Wang F, Shi K, et al. Research on Trends and Key Technologies of Small Satellites [J]. International Journal of Science, 2014, 1(2):38-42.

[9] Pollitt C. Performance audit in Western Europe: trends and choices[J]. Critical perspectives on accounting, 2003, 14(1): 157-170.

[10] Han H, Sa Z. Performance Evaluation of Special Funds Based on Budget Management in Colleges and Universities[C]//Proceedings of the 2nd International Conference on Green Communications and Networks 2012 (GCN 2012): Volume 3. Springer Berlin Heidelberg, 2013: 381-388. 